\title{
Can Nurturing the Young Be the Key to Tackling Chronic Diseases in the Old? A Narrative Review With a Global Perspective
}

\author{
Bethany Holt, BA, MBBS (Hons), ${ }^{1}$ Nayereh Kaviani, BSc, MedAdmin, ${ }^{2}$ Mehul Sheth, MD, ${ }^{1,3}$ \\ Mieke van Driel, MD, MSc, $\mathrm{PhD}^{4}$ \\ ${ }^{1}$ Faculty of Medicine, The University of Queensland, Brisbane, Australia ${ }^{2}$ School of Medicine, Griffith University, Gold Coast, Australia \\ ${ }^{3}$ Department of Internal Medicine, Ochsner Clinic Foundation, New Orleans, LA ${ }^{4}$ Primary Care Clinical Unit, Faculty of Medicine, \\ The University of Queensland, Brisbane, Australia
}

Background: One of the greatest challenges in healthcare today is dealing with a growing burden of multimorbid chronic diseases in an aging population. Awareness is growing that a healthy start in life plays a critical role in reversing this trend, especially for young women, pregnant mothers, and children in their first 2 years of life.

Methods: We reviewed the international literature on early childhood nutrition and development, based on the landmark Lancet series on maternal and child nutrition and child development, and World Health Organization reports.

Results: Contemporary literature points to the importance of strategies that focus on early childhood for enhancing both health and socioeconomic outcomes. We discuss programs and initiatives that aim to improve the health of mothers and children at a global level, with a focus on high-income countries such as Australia and the United States.

Conclusion: Tackling the epidemic of chronic diseases requires a comprehensive life course approach that must include pregnant women and their young children. Healthcare systems and professionals play an important role. The health and well-being of the next generation must be everyone's business.

Keywords: Child development, child mortality, chronic disease, health services accessibility, healthy lifestyle, social determinants of health

Address correspondence to Mieke van Driel, MD, MSc, PhD, Primary Care Clincial Unit, Faculty of Medicine, L8 Health Sciences Building, Royal Brisbane and Women's Hospital, Brisbane, Queensland 4029, Australia.Tel: +61-7-336-55144. Email: m.vandriel@uq.edu.au

\section{INTRODUCTION}

Globally, approximately 40 million people die of chronic diseases each year, accounting for $70 \%$ of all deaths. ${ }^{1}$ Although the burden of chronic diseases, especially those related to lifestyle factors, is growing faster in low-income and middle-income countries (LMICs), high-income countries (HICs) are also bearing the brunt. In both the United States and Australia, an estimated 1 in 2 people has at least one chronic condition and 1 in 4 has more than one. ${ }^{2-4}$ Chronic disease is responsible for $39 \%$ of preventable hospitalizations, $30 \%$ of visits to general practice, and more than $70 \%$ of deaths in Australia, indicating the huge burden it places on both citizens and health systems. ${ }^{4}$

Chronic diseases are closely linked with poverty. ${ }^{5}$ Poverty creates the conditions for ill health through restricting options for healthy behaviors and healthcare access. Moreover, ample evidence shows that the social determinants of health in their own right have an effect on biological processes implicated in the development of chronic diseases. ${ }^{6,7}$ In turn, chronic illness can lead to poverty by limiting a person's ability to work and through the expenses associated with healthcare, leaving people trapped in a downward spiral of disease and deprivation. As Niessen et al summarized, "health creates wealth," and those who lack it are at a disadvantage. ${ }^{5}$

The impact of chronic diseases and multimorbidity on healthcare systems and healthcare costs is dramatic, and governments are desperately trying to curb this growth by promoting healthy lifestyles. ${ }^{8}$ However, despite decades of campaigns to encourage exercise, the world's population today, in HICs as well as LMICs, is sitting more and gaining weight. ${ }^{9,10}$ We clearly need to start doing things differently. A better understanding of the early life roots of chronic diseases has led to an increasing awareness that tackling the chronic disease epidemic in adults requires a comprehensive life course approach ${ }^{6,8}$ that must include pregnant women and their young children.

\section{INFANT AND CHILD HEALTH IN THE MILLENNIUM DEVELOPMENT GOALS ERA}

The world's children are living, growing, and learning more than ever before, but progress has not been the 
Table 1. Progress on Child Health and Education According to the Millennium Development Goal (MDG) Targets ${ }^{11}$

\begin{tabular}{llll}
\hline Child Health Indicator & \multicolumn{1}{c}{ Progress 1990-2015 } & MDG 2015 Target \\
\hline Under 5-year-old mortality & 91 to 43 deaths/1,000 live births & $53 \%$ reduction & $66 \%$ reduction \\
Neonatal mortality & 36 to 19 deaths/1,000 live births & $47 \%$ reduction & $66 \%$ reduction \\
Underweight & $25 \%$ to $14 \%$ of under 5-year-olds & $50 \%$ reduction \\
Primary education & $81 \%$ to $91 \%$ enrollment & $100 \%$ \\
\hline
\end{tabular}

same across the globe and has fallen short of the global Millennium Development Goal (MDG) targets for childhood mortality, underweight, and primary education (Table 1). ${ }^{11}$ Huge disparities still exist between HICs and LMICs. For example, sub-Saharan African children are more than 15 times more likely to die before their fifth birthday than children in HICs. ${ }^{12}$ In LMICs, children born in the poorest families are twice as likely to die as those from the wealthiest. ${ }^{12}$ This disparity is not restricted to the developing world. In HICs, disadvantaged populations suffer disproportionately. Babies born to indigenous Australian mothers and, in the United States, babies born to African American mothers are twice as likely to start life with low birth weight (a risk factor for neonatal death and childhood illness) than those born to nonindigenous and white non-Hispanic women. Additionally, babies born in remote communities or to mothers in the low- est socioeconomic classes are also at a disadvantage in both countries. ${ }^{11,13,14}$

\section{IMPORTANCE OF A GOOD START IN LIFE}

Awareness is growing that the MDGs have not adequately captured the full burden of childhood health and development. The Sustainable Development Goals (SDGs), which succeeded the MDGs from 2015, established 17 broader and ambitious targets addressing economic, social, and environmental dimensions of development in an integrated manner. ${ }^{15}$ The SDG framework adopts a holistic perspective of health in the early years. It measures whether children thrive to their full potential by ensuring they are wellnourished and grow; are educated early and protected from threats; and grow up in a clean, healthy environment free from poverty (Table 2). ${ }^{16}$ In $2010,43 \%$ of children in

Table 2. Areas of Child Well-Being Incorporated Into the Sustainable Development Goals (SDGs) ${ }^{16}$

\begin{tabular}{|c|c|c|}
\hline Well-Being Area & Child-Related SDG Indicators & $\begin{array}{l}\text { Related } \\
\text { SDG }\end{array}$ \\
\hline \multirow[t]{6}{*}{ Survive and thrive } & Under 5-year-old mortality, neonatal mortality, maternal mortality & SDG 3 \\
\hline & Births attended by skilled personnel, adolescent birth rate & \\
\hline & New HIV infections, malaria incidence & \\
\hline & Vaccinations (MCV1, DPT3) & \\
\hline & Access to essential health services & \\
\hline & $\begin{array}{l}\text { Stunting (chronic undernutrition), wasting (acute undernutrition), and } \\
\text { overweight }\end{array}$ & SDG 2 \\
\hline \multirow[t]{4}{*}{ Learn } & Children under 5 years developmentally on track & SDG 4 \\
\hline & Organized learning 1 year before primary school & \\
\hline & Reading and mathematics proficiency in lower secondary school & \\
\hline & Proportion of schools with access to WASH & \\
\hline \multirow{3}{*}{$\begin{array}{l}\text { Protection against violence, } \\
\text { exploitation, and harmful } \\
\text { practices }\end{array}$} & Violence against girls, child marriage, female genital mutilation/cutting & SDG 5 \\
\hline & Child labor & SDG 8 \\
\hline & $\begin{array}{l}\text { Intentional homicide, conflict-related deaths, violence from caregivers, } \\
\text { sexual violence on girls and boys under } 18 \text { years, birth registration }\end{array}$ & SDG 16 \\
\hline \multirow[t]{5}{*}{ Safe, clean environment } & Basic drinking water, sanitation, and hygiene services & SDG 1 \\
\hline & Mortality rate from household/ambient air pollution & SDG 3 \\
\hline & $\begin{array}{l}\text { Safely managed drinking water and sanitation services, handwashing } \\
\text { facilities, open defecation }\end{array}$ & SDG 6 \\
\hline & Use of clean fuels & SDG 7 \\
\hline & Deaths from natural disasters & SDG 13 \\
\hline Fair chance in life & $\begin{array}{l}\text { Extreme poverty, below national poverty line, multidimensional } \\
\text { poverty, social protection floors/system }\end{array}$ & SDG 1 \\
\hline
\end{tabular}

DTP3, diphtheria, tetanus, pertussis vaccine full series; HIV, human immunodeficiency virus; MCV1, measles-containing vaccine first dose; WASH, water, sanitation, and hygiene. 
LMICs were at risk of not reaching their development potential because of stunting (ie, chronic malnutrition) and poverty. ${ }^{17,18}$ The burden on children in HICs remains unclear. ${ }^{19}$ For example, while the United States performs well on childhood mortality and stunting, no nationally representative data on early childhood learning and protection from abuse and violence are available. ${ }^{16}$

Investing in nurturing care that addresses these risk factors gives children a good start in life and has enduring benefits on health, learning, and earning capacity ${ }^{20}$ with the potential to address the comorbid negative effects of chronic disease and socioeconomic disadvantage. Fetal life, infancy, and early childhood are times of rapid brain growth; development of cognitive, language, and emotional capacities ${ }^{21}$; and establishment of long-term control of metabolism. ${ }^{22}$ Consequently, these are also times of extreme vulnerability to the effects of poor nutrition and psychosocial stressors.

In terms of nutrition, the first 1,000 days of life, from conception until 2 years of age, are critical. Poor maternal health and poor nutrition before and during pregnancy increase the risk of intrauterine growth restriction ${ }^{23}$ that in turn increases the risk of stunting (or being short for your height, indicating chronic undernutrition). ${ }^{24}$ Poor feeding practices and infectious disease also contribute to stunting, a condition that is irreversible after the first 2 years of life. ${ }^{23,25}$ Undernutrition in the first 1,000 days increases the chances of becoming overweight in adulthood and of developing chronic disease risk factors such as high blood sugar, cholesterol, and blood pressure, especially if children rapidly gain weight after 2 years old. ${ }^{24}$ Early undernutrition is also associated with lower educational attainment and adult income, ${ }^{25,26}$ as well as restricted reproductive outcomes, as stunted women give birth to smaller babies. ${ }^{27}$ Stunting and poverty in early life are estimated to reduce adult income by up to $20 \%$. $^{28}$

Similarly, exposure to adverse experiences such as violence and poverty in early life is associated with a greater incidence of chronic disease (mental and physical) and lower education and income levels, especially when multiple risks accrue before 3 years of age. ${ }^{18,20,29,30}$ The evidence is the strongest for the increased risk of cardiovascular disease and its contributing factors (eg, hypertension, diabetes, obesity), ${ }^{30}$ a leading cause of adult morbidity and mortality in both high- and low-income countries. Poverty affects cognitive development directly through altered epigenetic and biological mechanisms $\mathrm{s}^{20,31,32}$ and indirectly because parents have fewer caregiving resources. ${ }^{33}$ The effects of poverty on development are evident in the first 1,000 days and continue into the second 1,000 days (from 2 to 5 years of age). ${ }^{18,30}$ These negative consequences of undernutrition and adversity also reduce growth and developmental outcomes in the next generation. ${ }^{27,30,31}$ In addition, children raised in economic hardship are more likely to adopt adverse health-related behaviors (because of limited access to nutritious food and safe physical activity), contributing to the risk of chronic disease. ${ }^{32}$ Addressing these risk factors early has the potential to stop the progression to chronic disease and disadvantage in adulthood and disrupt this vicious intergenerational cycle.

\section{Interventions That Provide a Good Start in Life}

A range of effective interventions targeting women and children support early childhood development and its long- term positive impacts. ${ }^{28,31}$ These interventions begin before conception with nutrition support and family planning for women of reproductive age; continue through pregnancy and the postpartum period with good antenatal and perinatal care; and carry through to childhood with activities promoting adequate nutrition, early learning, responsive parenting, and management of childhood illness. While nutrition interventions are most effective in the first 1,000 days of life, actions that improve child development and educational attainment (eg, nurturing caregiving and learning opportunities) are effective throughout the second 1,000 days and into the school years. ${ }^{4,30}$ Interventions in the first and second 1,000 days are some of the most cost-effective investments countries can make in population health and development. ${ }^{28,34}$ The interventions can be delivered in an integrated manner through existing maternal and child health services. ${ }^{31}$ Governments play a critical role in facilitating strong intersectoral coordination required for implementation. ${ }^{30}$

In terms of promoting good early nutrition, interventions supporting breastfeeding should be encouraged, and the Baby-Friendly Hospital Initiative, launched by the United Nations Children's Fund (UNICEF) and World Health Organization (WHO) in 1991, has given breastfeeding a global boost ${ }^{35}$; 152 countries have implemented this program. ${ }^{36} \mathrm{~A}$ baby-friendly maternity facility does not accept breast milk substitutes, feeding bottles, or teats and has implemented 10 steps to support successful breastfeeding. These steps include educating staff and mothers and facilitating immediate and on-demand breastfeeding. A systematic review of mostly observational studies from $19 \mathrm{HICs}$ and LMICs reports a dose-response relationship between the number of the 10 steps women are exposed to and breastfeeding outcomes. ${ }^{37}$ Data from the United States show a small but important increase in breastfeeding initiation (3.8\%) and exclusivity (4.5\%) among women from lower socioeconomic backgrounds. ${ }^{38}$ Breastfed children score better on IQ tests, and breastfeeding possibly has an effect on the development of overweight/obesity. ${ }^{39}$ Good nutrition and micronutrient supplementation in pregnant women also improve development outcomes. For instance, iodine supplementation before or during pregnancy has a significant impact on children's cognitive development ${ }^{31}$ and is now recommended in perinatal clinical guidelines. Smoking cessation in pregnant women through simple psychosocial interventions improves the baby's growth in utero. ${ }^{40}$

Providing nurturing care early in life includes parenting support. ${ }^{31}$ Parents who themselves grew up in conditions of distress with a lack of role models often struggle to be effective parents to their children. A number of early childhood interventions, such as the Home Instruction for Parents of Preschool Youngsters (HIPPY) program, focus on teaching and supporting parents. The HIPPY program uses an evidencebased curriculum that provides parents with books, activities, and skills to help them prepare their child for school. HIPPY parents spend 10-15 minutes per day 5 days per week with their child on the activities. They are supported by group meetings and home visits where role modeling is used to develop teaching skills. ${ }^{41,42}$ HIPPY has been shown to result in better educational outcomes in the children. ${ }^{42,43}$ In Brisbane, Australia, a HIPPY program is embedded in an indigenous primary healthcare service, facilitating a coordinated and holistic approach to health and well-being. ${ }^{43}$ 
Following publication of the first Lancet series on maternal and child nutrition in 2008, community, governmental, and international organizations partnered to put the importance of early nutrition at the forefront. In 2010, the nonprofit organization 1,000 Days was established, supported by the US and Irish governments and the Bill \& Melinda Gates Foundation. ${ }^{44}$ The organization draws policy-makers' attention to the critical first 1,000 days of life. Many countries have since created their own 1,000 Days programs, tailored to their specific needs. The 2016 report "Nourishing America's Future" found that while poor nutrition in the first 1,000 days is widespread across the United States, the "burden falls hardest on lowincome families and communities of color, leading to a concentration of poor health outcomes in these populations." 45 Almost 1 in 5 children under the age of 6 years is a member of a family that is not able to provide nutritious food.

The Australian version of 1,000 Days focuses on Aboriginal and Torres Strait Islander families ${ }^{46}$ who suffer from a disproportionate burden of disadvantage and ill health. ${ }^{47}$ First 1,000 Days Australia functions as a platform for education, research, and advocacy, as well as a conduit for community-led interventions. Funding for activities and projects is sourced from both governmental and private sectors. ${ }^{46}$ The unique approach of an indigenous-led engagement process empowers the affected population to be part of designing and implementing interventions that affect them. The program's use of a strengths-based model, which emphasizes the positive power of culture and elder wisdom, breaks with the traditional deficit model of disadvantage. Through involving researchers, policy makers, human rights activists, and indigenous organizations, First 1,000 Days Australia builds a foundation for evidence-based and widely supported interventions that have the best potential for success. The advocacy has already resulted in the concept of the First 1,000 days being included in state and national policy and strategic plans. In the field, First 1,000 Days Australia launched its first intervention in 2017 in the tropical north of Queensland. The program complements the local healthcare services aimed at tackling chronic diseases in the community by addressing the social determinants of health. It links available services and includes a focus on child protection, early-life literacy, the role of men, and other issues that impact indigenous parents and infants. ${ }^{46}$

\section{A ROLE FOR HEALTH PROFESSIONALS AND HEALTHCARE SYSTEMS}

The global intergovernmental institutions WHO and UNICEF have set the parameters for improving the health of women and children worldwide, and a body of research has developed the case and means for taking action. Now the onus is on individual governments to turn their population statistics in the right direction. Governments can facilitate change by creating appropriate policies and making funds available, but they will need to work in partnership with health system actors, with the private and nonprofit sectors, and with passionate people who make it all happen.

We have discussed a number of global and national initiatives, but the small or unnoticed projects on our own doorsteps define the success of policies and high-level commitments. Health professionals at all levels of the healthcare system have an important role to play. The example of the HIPPY program (supported by the Australian govern- ment) operating within a primary care service demonstrates how a non-health-related program can be integrated successfully in a privately run community health service. Primary care lends itself particularly well to such an integrated and holistic approach as it is rooted in the community and looks after patients' physical, mental, and social well-being.

The Ochsner-Bonnabel High School public/private partnership in New Orleans, LA supports a school-based health center (SBHC) and illustrates the commitment of health systems to support children and parents living in poverty and disadvantage. Started as part of the state's 1991 Adolescent School Health Initiative, SBHCs provide comprehensive medical and mental health services and are strategically located in schools with high-risk student populations to address gaps in care. The SBHC at Bonnabel High School provides students with easily accessible healthcare, timely effective medical treatment, and continuity of care for common and chronic conditions such as asthma to reduce school absenteeism. The SBHC emphasizes preventive and proactive care through health screening and risk assessments, including mental illness. It evidently provides needed, equitable care, with roughly 300 general visits and 115 mental health visits per month; $41 \%$ of patients are uninsured. The SBHC also promotes healthy lifestyles in collaboration with the student-run Wellness Council. The Bonnabel program's success, nationally recognized by the Alliance for a Healthier Generation for its efforts to address childhood obesity, attests to the importance of dedicated programs for high-risk populations to turn their health outcomes around. ${ }^{48}$

The SBHC approach has been adopted across the United States and is associated with not only a range of positive health impacts ${ }^{49}$ but also improved school attendance and academic performance. ${ }^{50}$ In some contexts, SBHCs have been used to provide prenatal and antenatal care for adolescents and have been associated with lower rates of low-birth weight infants compared to standard hospital-based care. ${ }^{51}$ This outcome exemplifies how existing community health platforms that deliver services to young women can be used to implement interventions targeting the first 1,000 days of life, in addition to addressing the risk factors for chronic disease in older children and young adults. Additionally, the adolescents accessing SBHCs often come from socioeconomic disadvantage and may live in single-parent families and care for younger siblings. Therefore, working to improve their health and education outcomes can have an immediate impact on their own families, as well as their future children.

\section{SHIFTING TO AN INVERSE-CARE LENS}

Caring for the young and future generations is the key to tackling the current epidemic of chronic disease. There still is a way to go, especially for LMICs. Although the statistics on the health of women and children in HICs compare favorably to LMICs, there is no place for complacency. The existing healthcare disparities within resource-rich and highly developed countries call for an inverse-care approach. ${ }^{52}$ This concept, launched by Sir Julian Tudor Hart in 1971 is, in 2018, still embarrassingly relevant.

\section{CONCLUSION}

Aiming for long-term success in tackling the epidemic of chronic diseases requires a comprehensive life course 
approach that begins early and looks to those who are commonly overlooked: women and children of disadvantaged communities. By collaborating across sectors to enhance health and development in early life, we can build a healthier, better future for all. The health and well-being of the next generation must be everyone's business.

\section{ACKNOWLEDGMENTS}

The authors have no financial or proprietary interest in the subject matter of this article.

\section{REFERENCES}

1. Global Health Observatory $(\mathrm{GHO})$ data. Noncommunicable diseases (NCD). World Health Organization. www.who.int/gho /ncd/en/. Published 2018. Accessed April 13, 2018.

2. Vogeli $C$, Shields $A E$, Lee TA, et al. Multiple chronic conditions: prevalence, health consequences, and implications for quality, care management, and costs. J Gen Intern Med. 2007 Dec; 22 Suppl 3:391-395. doi: 10.1007/s11606-007-0322-1.

3. Ward BW, Schiller JS. Prevalence of multiple chronic conditions among US adults: estimates from the National Health Interview Survey, 2010. Prev Chronic Dis. 2013 Apr 25;10:E65. doi: 10.5888/pcd10.120203.

4. Australia's health 2016. Australia's health series no 15. Australian Institute of Health and Welfare. www.aihw.gov.au /reports/australias-health/australias-health-2016/contents /summary. Accessed September 28, 2018.

5. Niessen LW, Mohan D, Akuoku JK, et al. Tackling socioeconomic inequalities and non-communicable diseases in low-income and middle-income countries under the Sustainable Development agenda. Lancet. 2018 May 19;391 (10134):2036-2046. doi: 10.1016/S0140-6736(18)30482-3.

6. Lynch J, Smith GD. A life course approach to chronic disease epidemiology. Annu Rev Public Health. 2005;26:1-35. doi: 10.1146/annurev.publhealth.26.021304.144505.

7. Australia's health 2014. Australia's health series. Australian Institute of Health and Welfare. Canberra: AlHW, 2014. www .aihw.gov.au/reports/australias-health/australias-health-2014 /contents/table-of-contents. Accessed September 28, 2018.

8. Australian Health Ministers' Advisory Council. National Strategic Framework for Chronic Conditions. Australian Government. Canberra, 2017. www.health.gov.au/internet/main/publishing .nsf/content/nsfcc. Accessed September 28, 2018.

9. Abioye Al, Hajifathalian K, Danaei G. Do mass media campaigns improve physical activity? a systematic review and metaanalysis. Arch Public Health. 2013 Aug 2;71(1):20. doi: 10.1186/ 0778-7367-71-20.

10. NCD Risk Factor Collaboration (NCD-RisC). Trends in adult body-mass index in 200 countries from 1975 to 2014: a pooled analysis of 1698 population-based measurement studies with 19.2 million participants. Lancet. 2016 Apr 2;387(10026):13771396. doi: 10.1016/S0140-6736(16)30054-X.

11. Global Health Observatory (GHO) data. Health in 2015: from MDGs to SDGs. World Health Organization. www.who.int/gho /publications/mdgs-sdgs/en/. Published December 2015. Accessed September 28, 2018.

12. Children: reducing mortality. World Health Organization. www .who.int/mediacentre/factsheets/fs178/en/. Published October 31, 2017. Accessed September 28, 2018.

13. Children's headline indicators: low birthweight. Australian Institute of Health and Welfare. www.aihw.gov.au/reports /children-youth/childrens-headline-indicators/contents/3-low -birthweight. Updated August 6, 2018. Accessed September 28, 2018.
14. National survey of children's health, 2011/2012. Data and Resource Center for Child and Adolescent Health. childhealthdata.org/browse/data-snapshots/nsch-profiles /customizable-profile. Accessed September 28, 2018.

15. Nunes AR, Lee $K, O^{\prime}$ Riordan T. The importance of an integrating framework for achieving the Sustainable Development Goals: the example of health and well-being. BMJ Glob Health. 2016 Nov 24;1(3):e000068. doi: 10.1136/bmjgh-2016-000068.

16. UNICEF data: monitoring the situation of children and women: UNICEF. data.unicef.org/country/usa/. Accessed September 28, 2018.

17. Maternal and child nutrition. Executive summary. The Lancet. www.thelancet.com/series/maternal-and-child-nutrition. Published June 6, 2013. Accessed September 28, 2018.

18. Black MM, Walker SP, Fernald LCH, et al; Lancet Early Childhood Development Series Steering Committee. Early childhood development coming of age: science through the life course. Lancet. 2017 Jan 7;389(10064):77-90. doi: 10.1016/S0140-6736 (16)31389-7.

19. Progress for every child in the SDG era. United Nations Children's Fund. data.unicef.org/wp-content/uploads/2018/03 /Progress_for_Every_Child_V4.pdf. Published March 2018. Accessed September 28, 2018.

20. Emerson L, Fox S, Smith C. Good beginnings: getting it right in the early years. Review of the evidence on the importance of a healthy start to life and on interventions to promote good beginnings. Lowitja Institute. www.lowitja.org.au/sites/default /files/docs/Early-Childhood-web.pdf. Published July 2015. Accessed September 28, 2018.

21. Health of children in "out-of-home" care: paediatric policy. Royal Australasian College of Physicians (RACP). www.racp.edu .au/docs/default-source/advocacy-library/health-of-children-in -out-of-home-care.pdf. Published 2006. Reviewed December 2008. Accessed September 28, 2018.

22. Bruce KD, Hanson MA. The developmental origins, mechanisms, and implications of metabolic syndrome. J Nutr. 2010 Mar;140(3):648-652. doi: 10.3945/jn.109.111179.

23. Victora CG. The millennium development goals and the inverse care law: no progress where it is most needed? J Epidemiol Community Health. 2008 Nov;62(11):938-939. doi: 10.1136/ jech.2008.081653.

24. Black RE, Bhutta ZA, Alderman H, Ruel M, Gillespie S, Haddad L. Maternal and child nutrition - authors' reply. Lancet. 2013 Nov 9;382(9904):1551-1552. doi: 10.1016/S0140-6736(13)62320-X.

25. de Onis M, Dewey KG, Borghi E, et al. The World Health Organization's global target for reducing childhood stunting by 2025: rationale and proposed actions. Matern Child Nutr. 2013 Sep;9 Suppl 2:6-26. doi: 10.1111/mcn.12075.

26. Victora C, Requejo J, Boerma T, et al; Countdown to 2030. Countdown to 2030 for reproductive, maternal, newborn, child, and adolescent health and nutrition. Lancet Glob Health. 2016 Nov;4(11):e775-e776. doi: 10.1016/S2214-109X(16)30204-2.

27. Victora CG. Nutrition in early life: a global priority. Lancet. 2009 Oct 3;374(9696):1123-1125. doi: 10.1016/S0140-6736(09)61725-6.

28. Bhutta ZA, Das JK, Rizvi A, et al; Lancet Nutrition Interventions Review Group, the Maternal and Child Nutrition Study Group. Evidence-based interventions for improvement of maternal and child nutrition: what can be done and at what cost? Lancet 2013 Aug 3;382(9890):452-477. doi: 10.1016/S0140-6736(13) 60996-4.

29. Walker SP, Wachs TD, Grantham-McGregor S, et al. Inequality in early childhood: risk and protective factors for early child development. Lancet. 2011 Oct 8;378(9799):1325-1338. doi: 10.1016/S0140-6736(11)60555-2. 
30. Black MM, Pérez-Escamilla R, Rao SF. Integrating nutrition and child development interventions: scientific basis, evidence of impact, and implementation considerations. Adv Nutr. 2015 Nov;6(6):852-859. doi: 10.3945/an.115.010348.

31. Britto PR, Lye SJ, Proulx K, et al; Early Childhood Development Interventions Review Group, for the Lancet Early Childhood Development Series Steering Committee. Nurturing care: promoting early childhood development. Lancet. 2017 Jan 7;389(10064):91-102. doi: 10.1016/S0140-6736(16)31390-3.

32. Wise PH. Child poverty and the promise of human capacity: childhood as a foundation for healthy aging. Acad Pediatr. 2016 Apr;16(3 Suppl):S37-S45. doi: 10.1016/j.acap.2016.01.014.

33. Horton R, Lo S. Nutrition: a quintessential sustainable development goal. Lancet. 2013 Aug 3;382(9890):371-372. doi: 10.1016/S0140-6736(13)61100-9.

34. Hoddinott J, Behrman JR, Maluccio JA, et al. Adult consequences of growth failure in early childhood. Am J Clin Nutr. 2013 Nov;98(5):1170-1178. doi: 10.3945/ajcn.113.064584.

35. The baby-friendly hospital initiative. United Nations Children's Fund. www.unicef.org/programme/breastfeeding/baby.htm. Accessed April 13, 2018.

36. Nutrition: baby-friendly hospital initiative. World Health Organization. www.who.int/nutrition/topics/bfhi/en/. Accessed July 19, 2018.

37. Pérez-Escamilla R, Martinez JL, Segura-Pérez S. Impact of the baby-friendly hospital initiative on breastfeeding and child health outcomes: a systematic review. Matern Child Nutr. 2016 Jul;12(3):402-417. doi: $10.1111 / \mathrm{mcn} .12294$.

38. Hawkins SS, Stern AD, Baum CF, Gillman MW. Evaluating the impact of the baby-friendly hospital initiative on breastfeeding rates: a multi-state analysis. Public Health Nutr. 2015 Feb;18(2):189-197. doi: 10.1017/S1368980014000238.

39. Horta BL, Victora CG. Long-term effects of breastfeeding: a systematic review. World Health Organization. apps.who.int/iris /handle/10665/79198. Published 2013. Accessed September 28, 2018.

40. Chamberlain C, O'Mara-Eves A, Porter J, et al. Psychosocial interventions for supporting women to stop smoking in pregnancy. Cochrane Database Syst Rev. 2017 Feb 14;2: CD001055. doi: 10.1002/14651858.CD001055.pub5.
41. HIPPY Australia. Hippy Australia, Families Learning Together. hippyaustralia.bsl.org.au/. Accessed July 19, 2018.

42. HIPPY USA. Home Instruction for Parents of Preschool Youngsters. www.hippyusa.org. Accessed July 13, 2018.

43. Bowes J, Grace R. Review of early childhood parenting, education and health intervention programs for indigenous children and families in Australia. Australian Government. Australian Institute of Health and Welfare. apo.org.au/system /files/38115/apo-nid38115-21236.pdf. Published February 2014. Accessed September 28, 2018.

44. 1,000 Days. thousanddays.org/about/our-story/. Accessed July 13, 2018.

45. The first 1,000 days: nourishing America's future. 1,000 Days. thousanddays.org/resource/nourishing-americas-future. Published 2016. Accessed September 28, 2018.

46. First 1,000 Days Australia. www.first1000daysaustralia.org.au/. Accessed September 28, 2018.

47. Arabena K. The First 1000 Days: catalysing equity outcomes for Aboriginal and Torres Strait Islander children. Med J Aust. 2014 May 5;200(8):442.

48. Alfred Bonnabel High School Wins National Healthy Schools Silver Award. Alliance for a Healthier Generation. www .healthiergeneration.org/about_childhood_obesity/wellness_ stories/2015/12/04/1414/alfred_bonnabel_high_school_wins_ national_healthy_schools_silver_award. Published December 4, 2015. Accessed April 16, 2018.

49. Keeton V, Soleimanpour S, Brindis CD. School-based health centers in an era of health care reform: building on history. Curr Probl Pediatr Adolesc Health Care. 2012 Jul;42(6):132-156; discussion 157-158. doi: 10.1016/j.cppeds.2012.03.002.

50. Walker SC, Kerns SE, Lyon AR, Bruns EJ, Cosgrove TJ. Impact of School-Based Health Center use on academic outcomes. J Adolesc Health. 2010 Mar;46(3):251-257. doi: 10.1016/j. jadohealth.2009.07.002.

51. Barnet B, Duggan AK, Devoe M. Reduced low birth weight for teenagers receiving prenatal care at a school-based health center: effect of access and comprehensive care. $J$ Adolesc Health. $2003 \mathrm{Nov}$;33(5):349-358.

52. Hart JT. The inverse care law. Lancet. 1971 Feb 27;1(7696):405-412.

This article meets the Accreditation Council for Graduate Medical Education and the American Board of Medical Specialties Maintenance of Certification competencies for Patient Care, Medical Knowledge, and Practice-Based Learning and Improvement. 